\title{
Effectiveness of Lifestyle and Drug Intervention on Hypertensive Patients: a Randomized Community Intervention Trial in Rural China
}

\author{
Jing Xiao, $M D, P h D^{1,2}$, Wen-Long Ren, $M D, P h D^{7}$, Yuan-Yuan Liang, $M D^{7}$, \\ Huan Shen, $M D^{7}$, Yue-Xia Gao, MD, PhD ${ }^{1,2}$, Min-Jie Chu, MD, PhD ${ }^{1,2}$, Zhou Li, BD ${ }^{7}$, \\ Xiao-Jian Wang, $M D^{3}$, Zuo-Feng Zhang, $M D, P h D^{2}$, Xun Zhuang, $M D, P h D^{1,2}$, and \\ Yong-Fu Yu, MD, PhD 2,4
}

\begin{abstract}
'Department of Epidemiology and Medical Statistics, School of Public Health, Nantong University, Nantong, Jiangsu, People's Republic of China; ${ }^{2}$ Department of Epidemiology, Fielding School of Public Health, University of California Los Angeles, Los Angeles, CA, USA; ${ }^{3}$ Department of Chronic Disease and Prevention, Center for Disease Control and Prevention of Haian, Nantong, People's Republic of China; ${ }^{4}$ Department of Clinical Epidemiology, Aarhus University, Aarhus, Denmark.
\end{abstract}

BACKGROUND: Strict medication guidance and lifestyle interventions to manage blood pressure (BP) in hypertensive patients are typically difficult to follow.

OBJECTIVE: To evaluate the 1-year effectiveness of lifestyle and drug intervention in the management of rural hypertensive patients.

DESIGN: Randomized community intervention trial.

PARTICIPANTS: The control group comprised 967 patients who received standard antihypertensive drug intervention therapy from two communities, whereas the intervention group comprised 1945 patients who received antihypertensive drug and lifestyle intervention therapies from four communities in rural China.

MAIN MEASURES: Data on lifestyle behaviors and BP measurements at baseline and 1-year follow-up were collected. A difference-in-difference logistic regression model was used to assess the effect of the intervention.

KEY RESULTS: BP control after the 1-year intervention was better than that at baseline in both groups. The within-group change in BP control of $59.3 \%$ in the intervention group was much higher than the $25.2 \%$ change in the control group $(P<0.001)$. Along with the duration of the follow-up period, systolic and diastolic BP decreased rapidly in the early stages and then gradually after 6 months in the intervention group $(P<0.001)$. In the intervention group, drug therapy adherence was increased by $39.5 \%$ (from $48.1 \%$ at 1 month to $87.6 \%$ at 1 year) $(P<0.001)$, more in women $(45.6 \%)$ than in men (31.2\%; $P<0.001)$. The net effect of the lifestyle intervention improved the rate of BP control by $56.1 \%$ (70.8\% for men and $44.7 \%$ for women). For all physiological and

Jing Xiao, Wen-Long Ren and Yuan-Yuan Liang contributed equally to this work

Zuo-Fena Zhang is a co-senior author

Electronic supplementary material The online version of this article (https://doi.org/10.1007/s11606-019-05601-7) contains supplementary material which is available to authorized users.

Received January 21, 2019

Revised July 31, 2019

Accepted November 7, 2019

Published online October 6, 2020 biochemical factors, such as body mass index, waist circumference, lipid metabolism, and glucose control, improvements were more significant in the behavioral intervention group than those in the control group (all $P<0.001)$.

CONCLUSION: The addition of lifestyle intervention by physicians or nurses helps control BP effectively and lowers BP better than usual care with antihypertensive drug therapy alone.

KEY WORDS: hypertension; lifestyle intervention; effectiveness; blood pressure control rate.

J Gen Intern Med 35(12):3449-57

DOI: $10.1007 / \mathrm{s} 11606-019-05601-7$

(C) Society of General Internal Medicine 2019

\section{INTRODUCTION}

The World Health Organization estimated that globally, approximately $40 \%$ of adults aged $\geq 25$ years have hypertension. ${ }^{1}$ Hypertension causes approximately 7.5 million deaths and 57 million disability-adjusted life years. ${ }^{2}$ It is the main risk factor for coronary artery disease (CAD), stroke, and heart failure and can lead to adverse effects on health if left uncontrolled. ${ }^{3}$ Improved management of hypertension can prevent strokes and heart attacks. ${ }^{4}$ Improving blood pressure (BP) control among hypertensive patients is a critical area of focus in clinical medicine. ${ }^{5}$ However, BP control rates remain poor. ${ }^{6}$ In 115 communities in China, the rate of awareness of hypertension was $41.6 \%$, rate of treatment was $34.4 \%$, and rate of control was only $8.2 \%$. $^{7}$

Simultaneous lifestyle modification and antihypertensive drug therapy has been considered effective for hypertension control. ${ }^{8}$ Lifestyle modifications such as dietary adjustments, smoking cessation, and regular exercise could reduce BP and prevent hypertension-related cardiovascular events. ${ }^{9}{ }^{10} \mathrm{How}-$ ever, the effectiveness of lifestyle interventions is still not well understood. Some previous studies on the effectiveness of 
lifestyle interventions had small sample sizes. The difficulty in implementing behavioral interventions through individual or home-based self-management methods ${ }^{11,12}$ poses a major challenge in conducting intervention studies with a large sample of hypertensive patients while simultaneously maintaining strict supervision of patient medication and lifestyle interventions by medical professionals. This is particularly difficult among rural Chinese patients because of the shortage of rural physicians in China and the bad connotation associated with intervention treatments among rural people, many of whom are migrant workers. Furthermore, suboptimal compliance with lifestyle interventions is often highly prevalent, with less than $10 \%$ of hypertensive adults fully compliant with dietary recommendations and 35\% compliant with exercise recommendations in developed countries. ${ }^{13,} 14$ Therefore, the effectiveness of lifestyle interventions needs to be investigated with a relatively large population in developing countries. We conducted the Haian Hypertension Patients Intervention Study (HHPIS) to evaluate the effectiveness of 1-year lifestyle intervention management on BP control and other biochemical variables among rural Chinese hypertensive patients.

\section{METHODS}

\section{Study Design}

We conducted a randomized community intervention trial to evaluate the effect of behavior intervention on BP control, using a within-group assessment with measurements obtained at baseline and after 1 year of follow-up (Fig. 1). At baseline, six Haian county communities with 12,892 participants aged 18-75 years were recruited for HHPIS and randomized into the control or intervention group in a 1:2 ratio. The control group comprised patients from two randomly chosen communities who received only standard drug intervention therapy. The intervention group comprised patients from four randomly chosen communities who received standard drug intervention therapy plus an additional lifestyle intervention. These communities operated independently. Their populations had comparable socioeconomic and cultural standings. Patients with essential hypertension (systolic blood pressure $[\mathrm{SBP}] \geq$ 140 or diastolic blood pressure $[\mathrm{DBP}] \geq 90 \mathrm{mmHg}$ ) or who were taking antihypertensive therapy were identified between March and May 2011 during in-person interviews. Patients who had secondary hypertension, a history of myocardial infarction or stroke within the preceding 3 months, or presence of communication barriers or other serious illnesses that could affect the diagnosis and treatment of hypertension were excluded. The Board of Scientific Research of Nantong University and the ethical committee of the Haian Center for Disease Control and Prevention approved the study protocol. All participants provided written informed consent.

\section{Intervention Method}

Community physicians and nurses administered the drug intervention therapy and additional lifestyle intervention. The study investigators held two 60-min training lectures at baseline and the end of 6 months and three 30-min group training sessions at the end of 3,9, and 11 months for community physicians and nurses to address optimal pharmaceutical therapies and lifestyle interventions for treating hypertension. After the survey questionnaires were collected at baseline, drug therapies were administered in the form of targeted drugs and dosages selected by community physicians based on the patients' BPs. The community physicians also monitored drug therapy adherence and the patients' BPs twice monthly during regular follow-ups, and provided appropriate medical advice and drug adjustments. The community physicians collected the daily record of the dosage of the antihypertensive medication taken from the patients every 2 weeks. Patients in the intervention group attended two 60-min individual counseling sessions every 4 weeks until the end of the study and were educated orally and in writing about eating foods with low salt and oil contents; increasing their intake of vegetables, fruits, and milk; consuming white meat (poultry) instead of red meat (beef, lamb, and pork); consuming fish at 1-2 meals per week; performing moderate (e.g., jogging and dancing) or vigorous (e.g., playing basketball or badminton) exercise for $\geq 3 \mathrm{~h}$ per week; and discontinuing smoking and drinking. Implementation of these instructions was monitored by the community physicians twice a month and by the community nurses every 3 days throughout the 1-year follow-up. The patients, community physicians, and nurses received no other intervention training. Data regarding lifestyle behaviors, biochemical factors, anthropometric measurements, and familial disease histories were collected from each participant in the two groups at baseline and at 1-year follow-up using standard questionnaires. The participants' BP and drug therapy adherence were evaluated and $\mathrm{BP}$ control was determined monthly. The rate of BP control was the proportion of patients with controlled BP among those taking antihypertension drugs. Drug therapy adherence was calculated as the dosage of antihypertensive medication taken divided by the amount prescribed for 1 month during the 1-year follow-up. Based on Chinese guidelines for the management of hypertension (treatment with antihypertensive drugs), we defined BP control as achieving $\mathrm{SBP}<140$ and $\mathrm{DBP}<90 \mathrm{mmHg}$ for general hypertensive patients; $\mathrm{SBP}<130$ and $\mathrm{DBP}<80 \mathrm{mmHg}$ for hypertensive patients with diabetes, coronary heart disease, or chronic nephrotic; and $\mathrm{SBP}<150$ and $\mathrm{DBP}<90 \mathrm{mmHg}$ for elderly hypertension patients aged $\geq 65$ years. ${ }^{15}$

\section{Anthropometric and Biochemical Measurements}

At baseline and 1-year follow-up, weights and waist circumferences were measured twice. If the difference between the two measurements exceeded $1 \mathrm{~kg}$ or $1 \mathrm{~cm}$, a third 


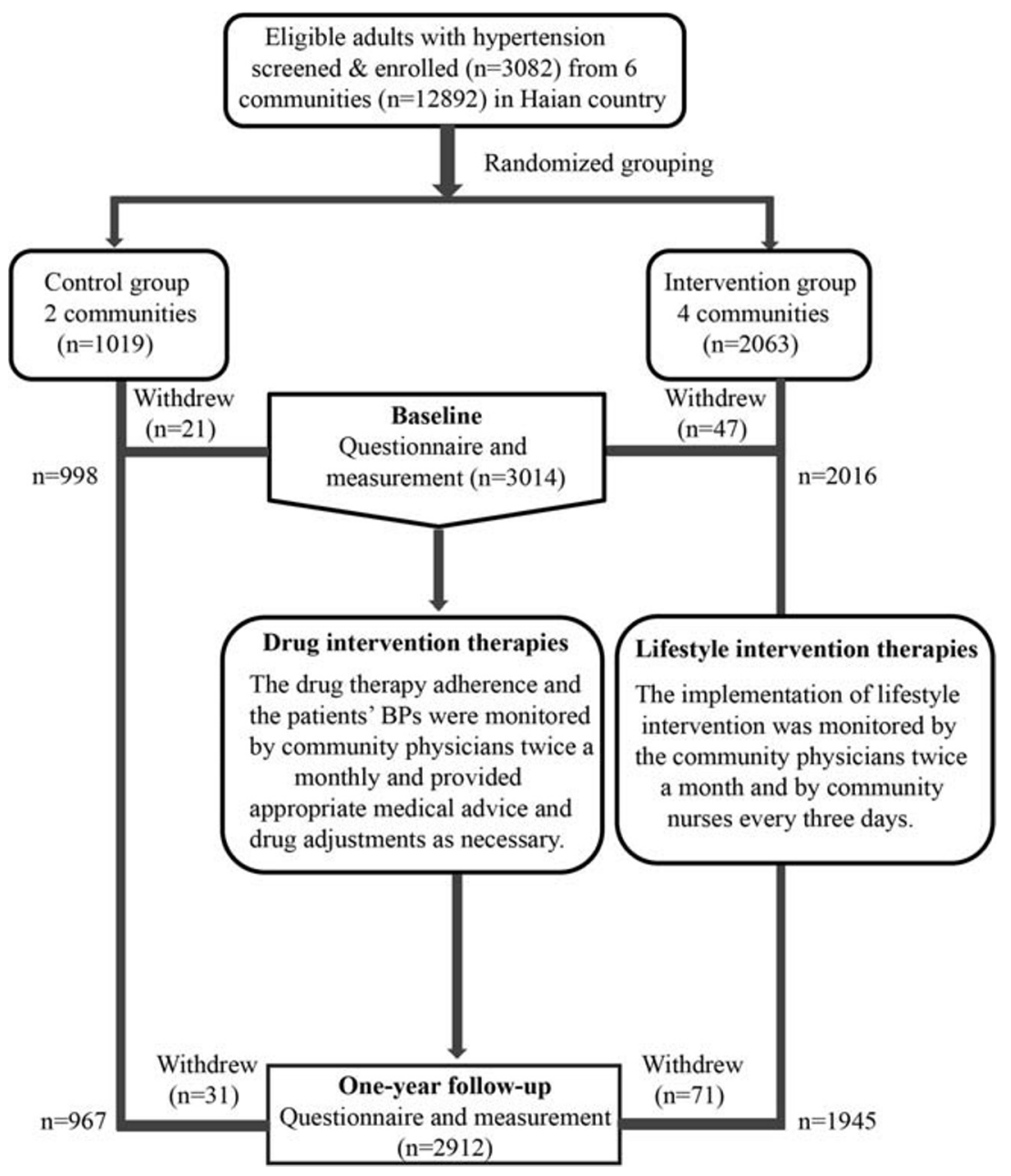

Fig. 1 Study design and flow of participants in the randomized community trial.

measurement was taken. The average coefficients for the intraobserver variation were both $<0.2 \%$. Therefore, the average of the two readings was used.

SBP and DBP were measured three times at both baseline and 1-year follow-up by community nurses after the participants had rested for $5 \mathrm{~min}$ or longer. The average of the three measurements was used. Overnight fasting blood samples were drawn at baseline and 1-year follow-up. The length of fasting times was verified to be at least $8 \mathrm{~h}$. Serum total cholesterol (TC), triglyceride (TG), high-density lipoprotein cholesterol (HDL-c), fasting blood glucose (FBG) and serum creatinine $(\mathrm{SCr})$ levels were measured enzymatically using an automated chemistry analyzer (Beckman Coulter AU480Beckman Coulter, Brea, CA, USA) within $6 \mathrm{~h}$ of the sample separation. All tests were conducted in the Haian Center for Disease Control and Prevention. Blinded sample quality control was conducted in the Jiangsu Provincial Center for Disease Control and Prevention.

\section{Lifestyle Factors and Disease History}

Smokers were defined as patients who had smoked $\geq 1$ cigarette per day during the previous month. Drinkers were defined as patients who consumed $>0.5$ ounces of pure alcohol per week during the previous month, which was equivalent to 4 ounces of grape wine, 4.8 ounces of rice wine, 12 ounces of beer, or 1 ounce of liquor. ${ }^{16}$ Patients were questioned about their familial histories of hypertension, CAD, stroke, and diabetes. We evaluated the frequency at which they consumed fruits and vegetables (daily, weekly, monthly, yearly, or never), and the amount consumed in liang ( 1 liang $=50 \mathrm{~g}$ ) per unit of time. Exercise was defined by moderate and vigorous physical activities ( $\geq 3 \mathrm{~h}$ per week of aerobic exercise) and daily participation in strengthening exercises during leisure time. Each participant was evaluated at baseline and 1-year follow-up.

\section{Statistical Analyses}

Continuous variables are described as means \pm standard deviations $(\bar{x} \pm s)$. We used the paired t test to compare values within and the t test to compare within-group changes between groups. Two-way analysis of variance was used to determine the interaction effect between the intervention method and intervention time in the multiplication model. Categorical variables are expressed as percentages and were 
compared between groups and between groups difference in within-group changes using Pearson's chi-square and withingroup difference using paired chi-square tests. We also compared between groups difference in within-group changes using the Mann-Whitney U test if the changes were positive for one and negative for another. A difference-in-difference (DID) logistic regression model was used to assess the net effect of the intervention, ${ }^{17}$ from which we estimated odds ratios (ORs) and 95\% confidence intervals (CIs). All statistical analyses were performed using SAS 9.4 software (SAS Institute, Cary, NC, USA) and considered statistically significant if $P$ values $<0.05$.

\section{RESULTS}

\section{Baseline Characteristics}

At enrollment, the control group comprised 1019 individuals from two communities and the intervention group comprised 2063 individuals from four different communities. There were 52 individuals who withdrew from the control group and 118 who withdrew from the intervention group (Fig. 1). After 1year follow-up, 2912 patients completed follow-up questionnaires ( 967 patients in the control group with a response rate of 98.2\% and 1945 patients in the intervention group with a response rate of $95.9 \%$ ), 426 of whom were newly diagnosed. In general, the intervention group was less educated and more likely to be farmers than were the control group. Furthermore, the percentages of patients newly diagnosed with hypertension were similar in the intervention (14.8\%) and control groups (14.3\%) (Table 1).

\section{Intervention Effectiveness on BP Treatment and Control}

The percentage of participants who received pharmaceutical treatments gradually increased in the intervention group $(P<0.001)$ and reached $100 \%$ at the end of the 1 -year follow-up (Fig. 2). In this group, patients' adherence to medication increased steadily with the duration of the follow-up period $(P<0.001)$, from $48.1 \%$ at the 1 -month follow-up to $87.6 \%$ (91.9\% among women and $81.8 \%$ among men), which was higher than the $57.2 \%$ in the control group at the end of the 1-year follow-up (Table 2). Adherence was stable among male patients $(P>0.05)$ and increased continually among female patients $(P<0.05)$ at 9-month and 1-year follow-up.

$\mathrm{BP}$ control and the duration of the follow-up increased from baseline to the 9-month follow-up $(P<0.001)$ and tended to be stable after that in the intervention group (Fig. 2). Better BP control was observed at the 1-year follow-up than at baseline (the within-group change of BP control of $59.3 \%$ in the intervention group was greater than the $25.2 \%$ change in the control group $(P<0.001)$ ) (Table 2$)$. Moreover, SBP/DBP decreased rapidly in the early stages and gradually after the 6-month follow-up $(P<0.001)$ in the intervention group (Fig. 2 ). By the end of 1-year follow-up, the corresponding within-
Table 1 Baseline Characteristics of Rural Hypertensive Patients.

\begin{tabular}{|c|c|c|c|}
\hline Variables & $\begin{array}{l}\text { Intervention group } \\
(n=1945)\end{array}$ & $\begin{array}{l}\text { Control group } \\
(n=967)\end{array}$ & $P$ \\
\hline $\begin{array}{l}\text { Age at interview } \\
(\bar{x} \pm s, y r s)\end{array}$ & $57.72 \pm 7.50$ & $58.05 \pm 8.86$ & 0.325 \\
\hline $\begin{array}{l}(x \pm s, y r s) \\
\text { Course of } \\
\text { hypertension } \\
(\bar{x} \pm s, y r s)\end{array}$ & $5.22 \pm 4.06$ & $5.30 \pm 3.09$ & 0.561 \\
\hline $\begin{array}{l}\text { Men } \\
\text { Women }\end{array}$ & $\begin{array}{l}829(42.6) \\
1116(57.4)\end{array}$ & $\begin{array}{l}380(39.3) \\
587(60.7)\end{array}$ & 0.086 \\
\hline \multicolumn{4}{|c|}{ New cases $(n(\%))$} \\
\hline $\begin{array}{l}\text { Yes } \\
\text { No }\end{array}$ & $\begin{array}{l}288(14.8) \\
1657(85.2)\end{array}$ & $\begin{array}{l}138(14.3) \\
829(85.7)\end{array}$ & 0.700 \\
\hline \multicolumn{4}{|c|}{ Marital status $(n(\%))$} \\
\hline $\begin{array}{l}\text { Single } \\
\text { Married } \\
\text { Divorced/ } \\
\text { widowed }\end{array}$ & $\begin{array}{l}25(1.3) \\
1802(92.6) \\
118(6.1)\end{array}$ & $\begin{array}{l}7(0.7) \\
893(92.4) \\
67(6.9)\end{array}$ & 0.270 \\
\hline $\begin{array}{l}\text { Primary and } \\
\text { below }\end{array}$ & $1674(86.1)$ & $850(87.9)$ & \multirow[t]{2}{*}{$\begin{array}{l}<.001 \\
0.0\end{array}$} \\
\hline $\begin{array}{l}\text { Middle school } \\
\text { High school and } \\
\text { above }\end{array}$ & $\begin{array}{l}227(11.7) \\
44(2.2)\end{array}$ & $\begin{array}{l}66(6.8) \\
51(5.3)\end{array}$ & \\
\hline \multicolumn{4}{|l|}{ Farmer $(n(\%))$} \\
\hline $\begin{array}{l}\text { No } \\
\text { Yes }\end{array}$ & $\begin{array}{l}859(44.2) \\
1086(55.8)\end{array}$ & $\begin{array}{l}609(63.0) \\
358(37.0)\end{array}$ & $\begin{array}{l}< \\
0.001\end{array}$ \\
\hline \multicolumn{4}{|c|}{ Familial history of hypertension $(n(\%))$} \\
\hline $\begin{array}{l}\text { No } \\
\text { Yes }\end{array}$ & $\begin{array}{l}1616(83.1) \\
329(16.9)\end{array}$ & $\begin{array}{l}795(82.2) \\
172(17.8)\end{array}$ & 0.557 \\
\hline \multicolumn{4}{|c|}{ Familial history of CHD $(n(\%))$} \\
\hline $\begin{array}{l}\text { No } \\
\text { Yes }\end{array}$ & $\begin{array}{l}1916(98.5) \\
29(1.5)\end{array}$ & $\begin{array}{l}943(97.5) \\
24(2.5)\end{array}$ & 0.059 \\
\hline \multicolumn{4}{|c|}{ Familial history of stroke $(n(\%))$} \\
\hline $\begin{array}{l}\text { No } \\
\text { Yes }\end{array}$ & $\begin{array}{l}1917(98.6) \\
28(1.4)\end{array}$ & $\begin{array}{l}944(97.6) \\
23(2.4)\end{array}$ & 0.068 \\
\hline \multicolumn{4}{|c|}{ Familial history of diabetes $(n(\%))$} \\
\hline $\begin{array}{l}\text { No } \\
\text { Yes }\end{array}$ & $\begin{array}{l}1918(98.6) \\
27(1.4)\end{array}$ & $\begin{array}{l}947(97.9) \\
20(2.1)\end{array}$ & 0.170 \\
\hline \multicolumn{4}{|l|}{ Smokers $(n(\%))$} \\
\hline $\begin{array}{l}\text { No } \\
\text { Yes }\end{array}$ & $\begin{array}{l}1545(79.4) \\
400(20.6)\end{array}$ & $\begin{array}{l}777(80.3) \\
190(19.7)\end{array}$ & 0.562 \\
\hline \multicolumn{4}{|l|}{ Drinkers $(n(\%))$} \\
\hline $\begin{array}{l}\text { No } \\
\text { Yes }\end{array}$ & $\begin{array}{l}1496(76.9) \\
449(23.1)\end{array}$ & $\begin{array}{l}748(77.4) \\
219(22.6)\end{array}$ & 0.791 \\
\hline \multicolumn{4}{|c|}{ Exercising $(n(\%))$} \\
\hline $\begin{array}{l}\text { No } \\
\text { Yes }\end{array}$ & $\begin{array}{l}1535(78.9) \\
410(21.1)\end{array}$ & $\begin{array}{l}748(77.4) \\
219(22.6)\end{array}$ & 0.333 \\
\hline
\end{tabular}

CHD coronary heart disease, yrs years

group change of SBP/DBP of 14.0/9.7 mmHg in the intervention group was significantly higher than the $8.0 / 5.5 \mathrm{mmHg}$ change in the control group. Similar results were observed in both sexes, and there was no difference in the intervention effect between the sexes. The interactions between the intervention time and intervention method on BP (Table S4, online appendix) showed that lifestyle intervention therapy for hypertension further reduce SBP and DBP $(P<0.001)$.

\section{Intervention Effects on Behavioral Lifestyle Factors}

At baseline, the patients' behavioral lifestyle factors were similar between the intervention and control groups (Table S2, online appendix). All lifestyle factors significantly improved at the 1-year follow-up in the intervention group; however, in the control group, vegetable intake in women and drinker in men significantly improved. All lifestyle factors 

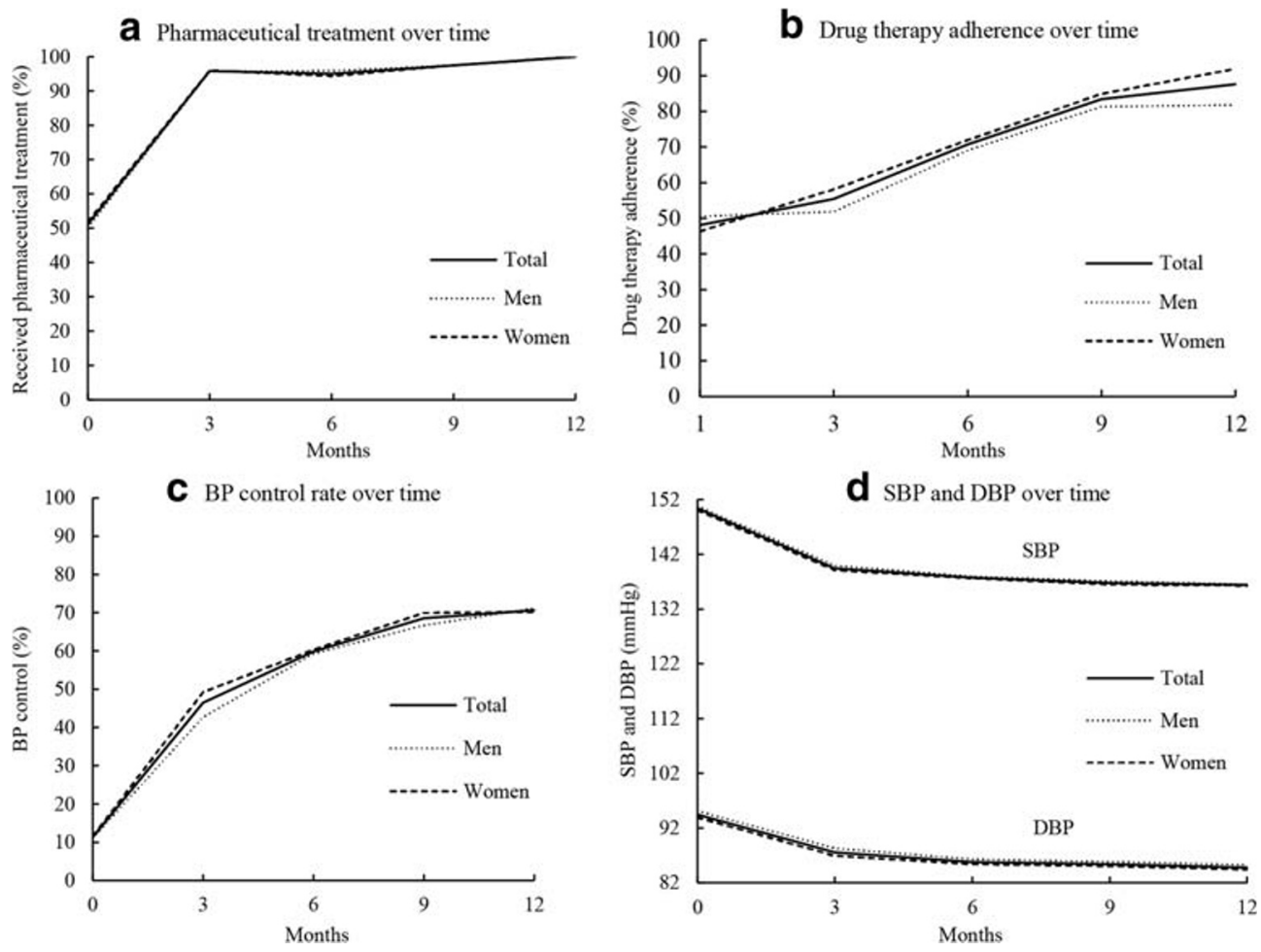

Fig. 2 Treatment, adherence, and blood pressure (BP) control, and systolic (SBP) and diastolic (DBP) blood pressure over time among hypertensive patients in the intervention group.

improved significantly more in the intervention group; there were significant intervention effects on the patients' behavioral lifestyles (Table S2, online appendix). For both sexes, there was a significantly improved change in the within-group values in the intervention group than in the control group (all $P<0.001$ ).

\section{Effects of Interventions on Physiological and Biochemical Factors}

As shown in Table S3 (online appendix), at the 1-year followup, BMI and waist circumference in men and TC, TG, FBG, $\mathrm{SCr}$, and HDL-c levels among both sexes were significantly improved in the intervention group (all $P$ value for withingroup change were $<0.05$ ). In the control group, many of these factors worsened or were unchanged in men and women; only the $\mathrm{SCr}$ level was significantly decreased in both sexes, but the within-group change was lower than that in the intervention group $(P<0.001)$. For all measures, improvements were larger in the behavioral intervention group than the control group (Table S4, online appendix). The proportions of patients taking lipid-lowering drugs were comparative in the intervention group (21.2\%) and control group (20.9\%) at the 1-year follow-up.

\section{Difference-in-Difference Logistic Regression Model of the Effects of Lifestyle Intervention on BP Control}

The OR for the intervention time was 2.156, indicating that the BP control rate increased by $115.6 \%$ (109.1\% for men and
$122.4 \%$ for women) at follow-up compared with baseline, regardless of intervention. The DID values indicated that the net effect of lifestyle interventions on hypertension increased the BP control rate by $56.1 \%$ (70.8\% for men and $44.7 \%$ for women) when offsetting the effect of drug therapy between the intervention and control groups (Table 3).

\section{DISCUSSION}

Lifestyle interventions, including dietary changes, increased exercise, and smoking and drinking cessation, have been shown to improve BP control rates ${ }^{18}$ and intensify the effects of antihypertensive medications. ${ }^{19} \mathrm{We}$ found that after 1 year of the aforementioned lifestyle interventions, the BP control rate in the lifestyle plus drug intervention group increased by $59.3 \%$, which is much higher than $25.2 \%$ in the control group. Our hypertension control rate is higher than that in Daugherty's report of 150,000 adults in the USA $(41.2 \%$ in men vs. $45.7 \%$ in women). ${ }^{20}$ The corresponding within-group deviation of SBP/DBP $14.0 / 9.7 \mathrm{mmHg}$ is significantly higher than $8.0 / 5.5 \mathrm{mmHg}$. Furthermore, previous studies have shown an inconsistent relationship in BP control between men and women. ${ }^{21,22}$ However, for both drug alone and drug plus lifestyle intervention treatment, the BP control rate showed non-significant differences in both sexes in our study. Further research should focus on the difference in BP between sexes regardless of the intervention. 


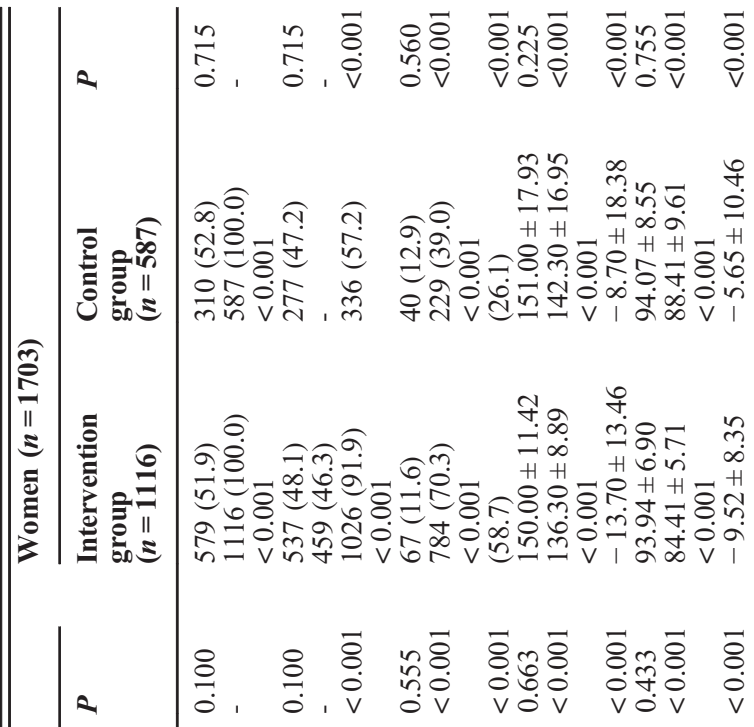

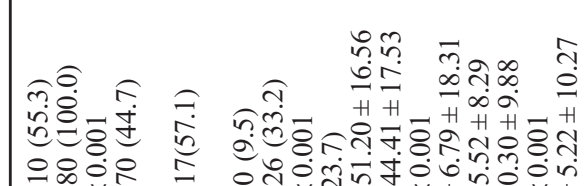
욤ㄴ,

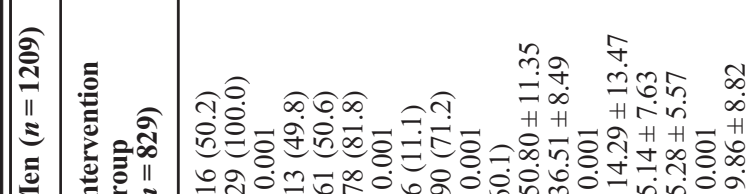

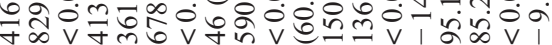

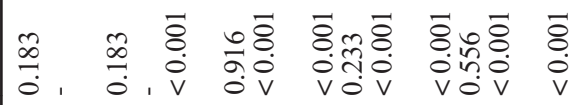<smiles>C[C@@H]1C[C@@H]2C[C@H]1[C@@H]1C[C@H]12</smiles> 


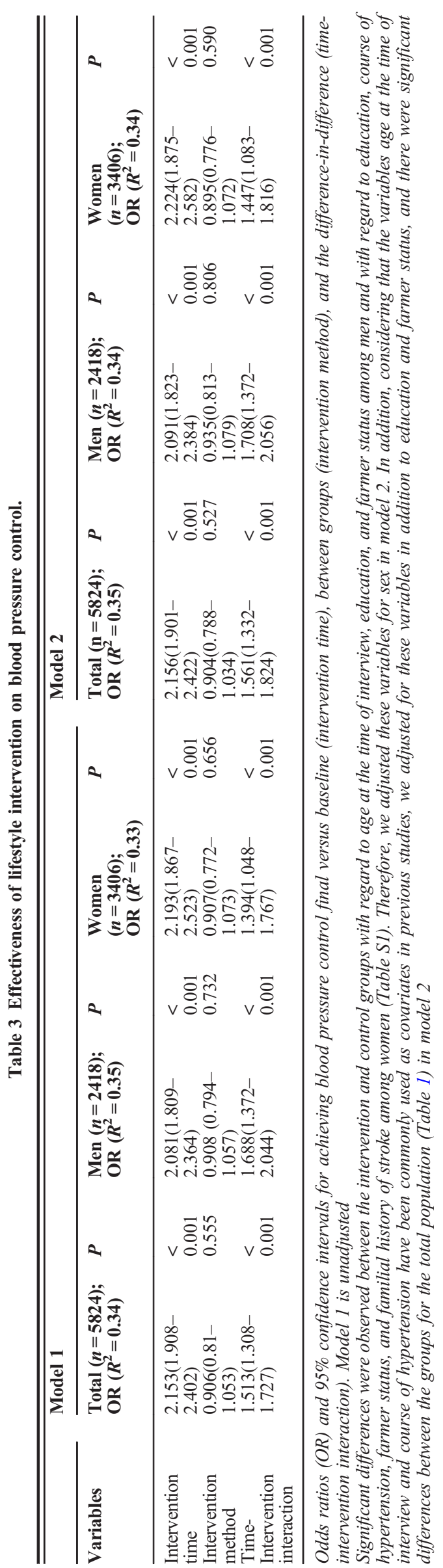

The Dietary Approaches to Stop Hypertension (DASH) intervention study clarified that diets rich in fruits and vegetables and low in fats and the DASH-sodium-restricted diet could reduce BP. ${ }^{23,}{ }^{24}$ However, these measures had no significant association with decreased BP among Korean ${ }^{14}$ and urban African American hypertensive patients. ${ }^{25}$ The DASH diet plus exercise significantly reduced the daytime ambulatory SBP. ${ }^{11}$ Generally, dietary patterns are not easily altered by basic education and supervision in a real-world clinical setting within a short period. Additionally, low compliance rates in these previous studies ${ }^{26}$ provided inconsistent conclusions. However, we observed significant BP-lowering effects related to primary exercise in combination with dietary interventions. The net effect of these lifestyle interventions improved the BP control rate by $56.1 \%$ ( $70.8 \%$ for men and $44.7 \%$ for women). Aerobic or resistance exercises control $\mathrm{BP}$, and regular exercise is recommended for the primary prevention of hypertension. ${ }^{27,}{ }^{28} \mathrm{We}$ considered that the total behavioral modification, including a combination of dietary modifications, exercise, decreased alcohol intake, and improved medication adherence as opposed to modifying only a single behavior, is important for improving the efficacy of lifestyle modification. That may also have been more effective for the control of hypertension.

In our study, drug therapy adherence increased by $39.5 \%$ through monitoring patient performance by community physicians and nurses for 1 year. Women's drug therapy adherence $(45.6 \%)$ increased more than men's $(31.2 \%)$ in the intervention group, which is consistent with some previous studies, ${ }^{29,}{ }^{30}$ but inconsistent with others considering that men were more effectively compliant with the therapies than women over the year of follow-up. ${ }^{31,32}$ Additionally, the improved medication adherence effect in the intervention group could also have contributed to improved BP control in this group. The effects of the behavior interventions on lifestyle factors were striking. The number of vegetables and fruits consumed and the proportion of patients exercising significantly increased, and the proportions of those consuming high-fat and high-salt diets and smokers and drinkers significantly decreased in the within-group change in the intervention group in both sexes. However, it is difficult for patients to make changes to lifestyle behaviors on their own, which may be a result of patients' perceptions of personal and social barriers to behavioral change. ${ }^{33}$ We identified these behaviors before designing the interventions, and before the initiation of strict monitoring and management by community physicians and nurses. The percentage of participants in our study who received pharmaceutical BP treatment significantly improved during the study and reached $100 \%$ in both groups after 1 year of follow-up, which is higher than the reported $50 \%$ in Chen et al.'s study, also conducted in China. ${ }^{34}$ Finally, lifestyle interventions helped increase drug therapy adherence. The drug therapy adherence $(87.6 \%)$ in the intervention group was higher than that in the control group (57.2\%) at the end of the 1-year follow-up period. This may because 
interventions affecting multiple behaviors promote each other more than two separate and unique behavioral changes. Moreover, epidemiological studies have established the association between hypertension and obesity, diabetes, lipid abnormalities, ${ }^{35,} 36$ and higher FBG levels. ${ }^{37}$ The net effect of our lifestyle intervention therapy in hypertensive patients led to lower BMI and waist circumferences in men and improved lipid metabolism and SCr levels and decreased glucose levels in both sexes; the control group did not have the same improvements.

The primary strength of this study is that it was conducted with a large population of rural Chinese adults with essential hypertension. Community physicians and nurses serving as the interventionists guided and monitored the antihypertensive drug and lifestyle intervention therapies regularly. There were also several potential limitations of the study. First, because of an imbalance in the development of primary healthcare in various regions in China, the study findings cannot be extrapolated to other populations among rural areas with poorer economic conditions. Second, self-reported adherence to medications and some lifestyle changes were based on the subjective judgments of the participants, which may have led to some biases. Finally, the duration of this study was relatively short (1 year), and some of the intervention effects may not be reflected sufficiently.

\section{CONCLUSIONS}

Drug interventions alone lowered the BP and improved BP control, while the intervention to improve overall lifestyle and adherence to medication contributed to further improvement of BP control and some physiological and biochemical factors after a 1-year intervention in hypertensive patients in rural China.

Acknowledgments: We deeply appreciate the participants of the Haian Hypertension Patients Intervention Study in Nantong, China, as well as Jiangsu Overseas Visiting Scholar Program for University Prominent Young \& Middle-aged Teachers and Presidents.

Corresponding Author: Xun Zhuang, MD, PhD; Department of Epidemiology and Medical Statistics, School of Public Health, Nantong University, Nantong, Jiangsu, People's Republic of China (e-mail: ntzhuang@163.com).

Funding information This study was funded by grants from the National Natural Science Foundation of China (31000539 and 71603137) and the Department of Science and Technology of Nantong (MS22016039 and MS12018052).

\section{Compliance with Ethical Standards:}

The Board of Scientific Research of Nantong University and the ethical committee of the Haian Center for Disease Control and Prevention approved the study protocol. All participants provided written informed consent.
Conflict of Interest: The authors declare no potential conflict of interests.

\section{REFERENCES}

1. World Health Organization (WHO). A Global Brief on Hypertension. n.d. Available at: http://www.who.int/cardiovascular_diseases/publications/ global_brief_hypertension/en/. Accessed November 7, 2019.

2. World Health Organization (WHO). Global Health Observatory Data. n.d. Available at: http://www.who.int/gho/ncd/risk_factors/blood_pressure_ prevalence_text/en/. Accessed November 7, 2019.

3. Benjamin EJ, Blaha MJ, Chiuve SE, et al. Heart disease and stroke statistics-2017 update: A report from the American Heart Association. Circulation. 2017;135:e146-603.

4. Frieden TR, King SM, Wright JS. Protocol-based treatment of hypertension: A critical step on the pathway to progress. JAMA. 2014;311:212.

5. Moran AE, Odden MC, Thanataveerat A, et al. Cost-effectiveness of hypertension therapy according to 2014 guidelines. N Engl J Med. 2015;372:447-55.

6. Wang YR, Alexander GC, Stafford RS. Outpatient hypertension treatment, treatment intensification, and control in Western Europe and the United States. Arch Intern Med. 2007;167:141-7.

7. Li W, Gu H, Teo KK, et al. Hypertension prevalence, awareness, treatment, and control in 115 rural and urban communities involving 47000 people from China. J Hypertens. 2016;34:39-46.

8. Weber MA, Schiffrin EL, White WB, et al. Clinical practice guidelines for the management of hypertension in the community a statement by the American society of hypertension and the international society of hypertension. J Hypertens. 2014;32:3-15.

9. Eckel RH, Jakicic JM, Ard JD, et al. 2013 AHA/ACC guideline on lifestyle management to reduce cardiovascular risk: a report of the American college of cardiology/American Heart Association Task Force on Practice Guidelines. Circulation. 2014;129(25 Suppl 2):S76-99.

10. Whelton SP, Chin A, Xin X, He J. Effects of aerobic exercise on blood pressure: A meta-analysis of randomized, controlled trials. Ann Intern Med. 2002;136:493-503.

11. Lee CJ, Kim JY, Shim E, et al. The effects of diet alone or in combination with exercise in patients with prehypertension and hypertension: A randomized controlled trial. Korean Circ J. 2018;48:637-51.

12. Niiranen TJ, Leino K, Puukka P, Kantola I, Karanko H, Jula AM. Lack of impact of a comprehensive intervention on hypertension in the primary care setting. Am J Hypertens. 2014;27:489-96.

13. Friedberg JP, Rodriguez MA, Watsula ME, et al. Effectiveness of a tailored behavioral intervention to improve hypertension control: primary outcomes of a randomized controlled trial. Hypertension. 2015;65:440-6.

14. Parikh A, Lipsitz SR, Natarajan S. Association between a DASH-like diet and mortality in adults with hypertension: findings from a populationbased follow-up study. Am J Hypertens. 2009;22:409-16.

15. Liu LS; Writing Group of Chinese Guidelines for the Management of Hypertension. 2010 Chinese guidelines for the management of hypertension. Zhonghua Xin Xue Guan Bing Za Zhi. 2011;39:579-615. [Article in Chinese]

16. Shu XO, Hatch MC, Mills J, Clemens J, Susser M. Maternal smoking, alcohol drinking, caffeine consumption, and fetal growth: results from a prospective study. Epidemiology. 1995;6:115-20.

17. Ye $\mathbf{F}$, Wang $\mathbf{Y}$. [Introduction and application of difference-in-differences model]. Chin J Health Stat.. 2013;30:131-4. [Article in Chinese]

18. Li Y, Wang $\mathbf{J L}$, Zhang $\mathbf{X C}$, et al. Effectiveness of adherence to standardized hypertension management by primary health care workers in China: A cross-sectional survey 3 years after the healthcare reform. Biomed Environ Sci. 2016;29:915-21.

19. Chobanian AV, Bakris GL, Black HR, et al. The Seventh Report of the Joint National Committee on Prevention, Detection, Evaluation, and Treatment of High Blood Pressure: The JNC 7 report. JAMA. 2003;289:2560-72.

20. Daugherty SL, Masoudi FA, Ellis JL, et al. Age-dependent gender differences in hypertension management. J Hypertens. 2011;29:1005-11.

21. Gu Q, Burt VL, Paulose-Ram R, Dillon CF. Gender differences in hypertension treatment, drug utilization patterns, and blood pressure control among US adults with hypertension: data from the National Health and Nutrition Examination Survey 1999-2004. Am J Hypertens. 2008;21:789-98. 
22. Ong KL, Tso AW, Lam KS, Cheung BM. Gender difference in blood pressure control and cardiovascular risk factors in Americans with diagnosed hypertension. Hypertension. 2008;51:1142-8.

23. Appel LJ, Moore TJ, Obarzanek E, et al. A clinical trial of the effects of dietary patterns on blood pressure. N Engl J Med. 1997;336:1117-24.

24. Sacks FM, Svetkey LP, Vollmer WM, et al. Effects on blood pressure of reduced dietary sodium and the Dietary Approaches to Stop Hypertension (DASH) diet. DASH-Sodium Collaborative Research Group. N Engl J Med. 2001;344:3-10.

25. Miller ER 3rd, Cooper LA, Carson KA, et al. A dietary intervention in urban African Americans: Results of the "five plus nuts and beans" randomized trial. Am J Prev Med. 2016;50:87-95

26. Kwan MW, Wong MC, Wang HH, et al. Compliance with the dietary approaches to stop hypertension (dash) diet: A systematic review. PLoS One. 2013;8:e78412.

27. Mancia G, Fagard R, Narkiewicz K, et al. 2013 Practice guidelines for the management of arterial hypertension of the European Society of Hypertension (ESH) and the European Society of Cardiology (ESC): ESH/ ESC Task Force for the Management of Arterial Hypertension. J Hypertens. 2013;31:1925-38.

28. Sharman JE, La Gerche A, Coombes JS. Exercise and cardiovascular risk in patients with hypertension. Am J Hypertens. 2015;28:147-58.

29. Ross S, Walker A, MacLeod MJ. Patient compliance in hypertension: Role of illness perceptions and treatment beliefs. J Hum Hypertens. 2004; 18:607-13.
30. Li WW, Wallhagen MI, Froelicher ES. Hypertension control, predictors for medication adherence and gender differences in older Chinese immigrants. J Adv Nurs. 2008;61:326-35.

31. Wong MC, Tam WW, Cheung CS, et al. Medication adherence to first-line antihypertensive drug class in a large Chinese population. Int $\mathrm{J}$ Cardiol. 2013;167:1438-42.

32. Chen SL, Lee WL, Liang T, Liao IC. Factors associated with gender differences in medication adherence: A longitudinal study. J Adv Nurs. 2014;70:2031-40

33. Devkota S, Dhungana RR, Pandey AR, et al. Barriers to treatment and control of hypertension among hypertensive participants: A communitybased cross-sectional mixed method study in municipalities of Kathmandu, Nepal Front Cardiovasc Med. 2016;3:26.

34. Chen LZ, Shi GT, Ding RJ, Hu DY. [The prevalence, awareness, and control of hypertension in xianghe county of hebei province]. Zhonghua Nei Ke Za Zhi.. 2013;52:185-7. [Article in Chinese]

35. Feinkohl I, Lachmann G, Brockhaus WR, et al. Association of obesity, diabetes and hypertension with cognitive impairment in older age. Clin Epidemiol. 2018;10:853-62.

36. Xiao J, Hua T, Shen H, et al. Associations of metabolic disorder factors with the risk of uncontrolled hypertension: A follow-up cohort in rural China. Sci Rep. 2017;7:743.

37. Emamian M, Hasanian SM, Tayefi M, et al. Association of hematocrit with blood pressure and hypertension. J Clin Lab Anal. 2017;31:e22124.

Publisher's Note Springer Nature remains neutral with regard to jurisdictional claims in published maps and institutional affiliations. 